\title{
Compact low-power mid-IR supercontinuum for sensing
}

Moselund, Peter M. ; Bowen, Patrick ; Huot, Laurent; Carthy, Joanna; Powell, Ross; Hooper, Lucy

Published in:

Proceedings of SPIE

Link to article, DOI:

$10.1117 / 12.2290447$

Publication date:

2018

Document Version

Peer reviewed version

Link back to DTU Orbit

Citation (APA):

Moselund, P. M., Bowen, P., Huot, L., Carthy, J., Powell, R., \& Hooper, L. (2018). Compact low-power mid-IR supercontinuum for sensing. In Proceedings of SPIE (Vol. 10540). SPIE - International Society for Optical Engineering. https://doi.org/10.1117/12.2290447

\section{General rights}

Copyright and moral rights for the publications made accessible in the public portal are retained by the authors and/or other copyright owners and it is a condition of accessing publications that users recognise and abide by the legal requirements associated with these rights.

- Users may download and print one copy of any publication from the public portal for the purpose of private study or research.

- You may not further distribute the material or use it for any profit-making activity or commercial gain

- You may freely distribute the URL identifying the publication in the public portal

If you believe that this document breaches copyright please contact us providing details, and we will remove access to the work immediately and investigate your claim. 


\title{
Compact low-power mid-IR supercontinuum for sensing applications
}

\author{
Peter M. Moselund ${ }^{\mathrm{a}}$, Patrick Bowen ${ }^{\mathrm{a}}$, Laurent Huot ${ }^{\mathrm{a}, \mathrm{b}}$, Joanna Carthy $^{\mathrm{c}}$, Ross Powell ${ }^{\mathrm{c}}$, Lucy Hooper $^{\mathrm{c}}$ \\ ${ }^{a}$ NKT Photonics DK, Blokken 84, 3620 Birkeroed, Denmark; \\ ${ }^{\mathrm{b}}$ Technical University of Denmark, Frederiksborgvej 399, 4000 Roskilde, Denmark \\ 'NKT Photonics UK, 20 Compass Point, Ensign Way, Southampton, SO31 4RA, United Kingdom
}

\section{ABSTRACT}

Mid-IR supercontinuum sources are a new type of source for the 2-4.5 $\mu \mathrm{m}$ spectrum, but their weight, size and power consumption has previously made them unsuitable for mobile sensing. We demonstrate a highly compact supercontinuum source with a weight of $<1 \mathrm{~kg}$ and a power consumption of $<15 \mathrm{~W}$ emitting a spectral brightness comparable to that of a synchrotron and covering the entire 1.8-4.4 $\mu \mathrm{m}$ spectrum. We will also discuss challenges and opportunities of working with a broadband source instead of a single line or tunable source and touch upon the future potential for supercontinuum reaching further into the mid-IR

Keywords: Supercontinuum, mid-IR, Spectroscopy, Sensing

\section{INTRODUCTION}

In recent years, interband cascade lasers (ICLs) and quantum cascade lasers (QCLs) have allowed impressive breakthroughs in mid-infrared (mid-IR) sensing applications, but the limited spectral bandwidth achievable from a single lightsource based on these technologies has made truly wideband spectroscopy applications challenging. As an alternative, one could use supercontinuum (SC) light sources which can deliver a high brightness continuous spectrum spanning several octaves and which have recently appeared as commercially available sources for the mid-IR after a decade of confinement to the visible to near-IR spectrum. Mid-IR light sources such as these have been already applied for mid-IR spectroscopy [1]-[3] and microscopy [4]-[6] and even proposed as a an "optical biopsy" [7][8], to replace current invasive biopsies. These demonstrations mostly relied on conventional mid-IR detectors but the high spatial coherence of SC sources also make them very suitable for mid-IR sensing based on up-conversion of the signal using sum frequency generation. This technique promises to allow much lower detection noise by shifting the light to the spectrum of much more sensitive silica and InGaAs detectors [1][9]-[11]. However, the application of mid-IR SC sources to sensing have so far been limited because their large size and weight $(>10 \mathrm{~kg})$ and relatively high power consumption $(\geq 100 \mathrm{~W})$ which has have made them unsuited for applications that require compact mobile systems.

The majority of the current SC sources are large because they are pumped with modelocked picosecond lasers with repetition rates in the tens of $\mathrm{MHz}$ which even though the pulses are very short, i.e. 5-10 ps, gives them relative high duty cycles on the order of 1:2000. As kilowatt level peak powers are required for the nonlinear processes generation the supercontinua this means that rather high average powers are required from the pump systems. This in turn means that the pump system becomes large, complex and power demanding and unsuited for low-power portable sensing applications.

However, for many sensing applications the high average power of these MHz SC sources is not necessary. If one reduces the repetition rate to tens of kilohertz one can bring down the average power of the sources by more than an order of magnitude while maintaining the wide spectrum. At the same time, one can adopt less complex, more compact and lower repetition rate seed sources than modelocked lasers at the cost of longer pulses. In total this allows the size, weight, power consumption and price of the sources to be greatly reduced. This has previously been demonstrated with silica sources covering the visible to near infrared spectrum $(0.5-2.5 \mu \mathrm{m})$ which lead to the development of the SuperK Compact SC source (See Fig. 1 left) which uses nanosecond pulses at $1 \mathrm{~Hz}-24 \mathrm{kHz}$ pulse repetition rates and is one of the most compact and the lowest cost SC source on the market.

We have carried out a similar simplification of the design for high power mid-IR SC sources which we have demonstrated previously [1][2] in order to create a low power mid-IR SC source with a repetition rate of 30-40 kHz. At the same time we have greatly simplified and compressed the electronics necessary to run the source in order to bring it down to a volume of $0.6 \mathrm{~L}$, a weight of $0.6 \mathrm{~kg}$ and a power consumption of $<15 \mathrm{~W}$. This highly compact source (see Fig. 1 right) is initially intended for operation in an airborne gas spectroscopy system for pollution monitoring which will be mounted in a drone 
as part of the EU project FLAIR[12]. Aside from this drone application this system could also be considered for other mobile applications as even with continuous operation it could run 3-4 hours on a standard laptop battery and much longer if only sampling measurements were required at intervals.
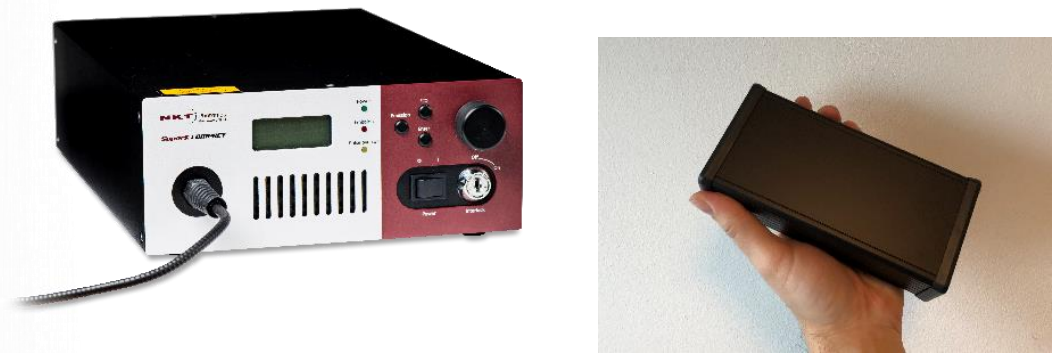

Fig. 1: Left Commercial silica kHz SC source. Right super compact lightweight fluoride fiber based SC source optimized for portable sensing applications.

Despite its compact size the system will still emit brightness on the level with previous silica based nanosecond SC sources and more than an order of magnitude more brightness than Synchrotrons IR beamlines, which have traditionally been the only broad bandwidth high brightness continuous spectrum source for this region (see Fig. 2).

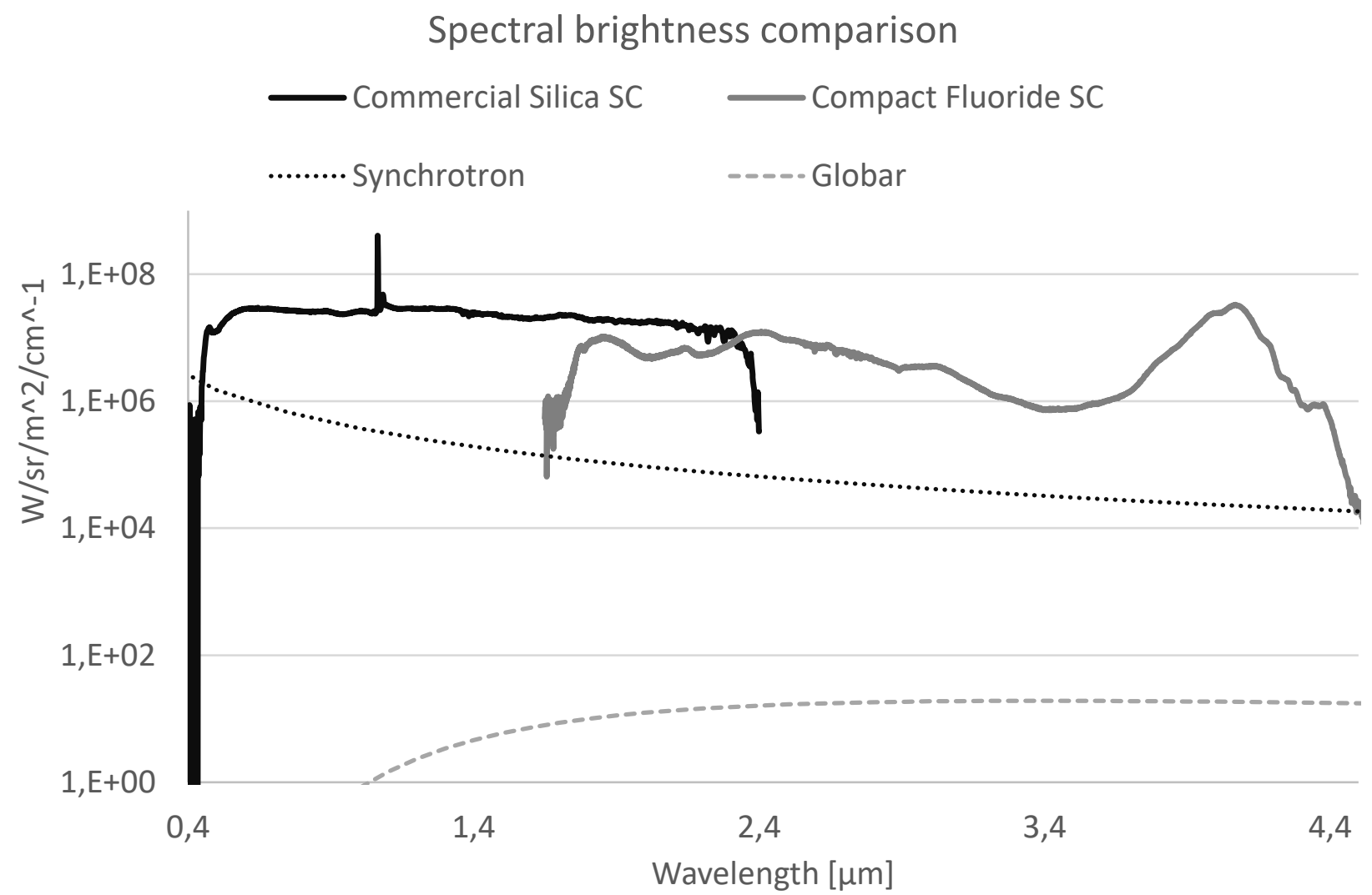

Fig. 2 Brightness of silica, Fluoride and Chalcogenide fiber based SC sources compared to a synchrotron and a globar ( $1500{ }^{\circ} \mathrm{K}$ blackbody). The synchrotron spectral brightness was calculated for a beam current of $0.5 \mathrm{~A}$ using the analytical approximation [13]. It was compared to reported spectral brightnesses of actual synchrotron beamlines at Diamond [14], NSLS [15] and SLS [16] reported in the literature and found to be equal or higher than these. 
The current source covers a spectrum of 1.8-4.4 $\mu \mathrm{m}$. However, we have shown elsewhere that with careful choice of fiber designs for the nonlinear fibers and other pump parameters similar fluoride fiber based sources has been shown to be extendable considerably further into the mid-IR [17]-[20] if chalcogenide fibers are added to the output. Thus, it is likely that if one used chalcogenide fibers to further broaden the spectrum of these sources one could increase the spectrum to cover at least up to 7-8 $\mu \mathrm{m}$ while maintaining the small footprint.

The reduction of the repetition rate from $\mathrm{MHz}$ to $\mathrm{kHz}$ and order of magnitude reduction in average power is not without consequences. It is well know that most SC sources have some pulse-to-pulse fluctuation in the generated spectral shape and averaging over many pulses is a well-established method to reduce the impact of this noise. In imaging applications where a large number of points may need to be scanned the added measurement time required for averaging can be unacceptable. However, in sensing applications where usually only a single point is evaluated it is very often sufficient with measurement times on the millisecond timescale or slower which will allow enough averaging for highly sensitive measurements. Thus it has recently been shown that with correctly chosen measurement conditions and integration times even $\mathrm{kHz}$ SC sources can still be applied to very noise sensitive applications such as Optical coherence tomography (OCT) [21]-[24]. An advantage of the longer pulses with lower repetition rate is also that they contain more energy per pulse and can therefore also be utilized for techniques requiring higher energies such as photoacoustic spectroscopy [22]-[26].

\section{CONCLUSION}

We have here demonstrated a highly compact, low power SC source covering the mid-IR range (1.8-4.4 $\mu \mathrm{m})$ it emits light with a brightness more than an order of magnitude higher than a synchrotron while maintaining a compact $0.6 \mathrm{~L}, 0.6 \mathrm{~kg}$ footprint and a low power consumption of $<15 \mathrm{~W}$ which could allow battery powered applications. To the knowledge of the authors, this is the SC source with the lowest power consumption and smallest footprint demonstrated to date.
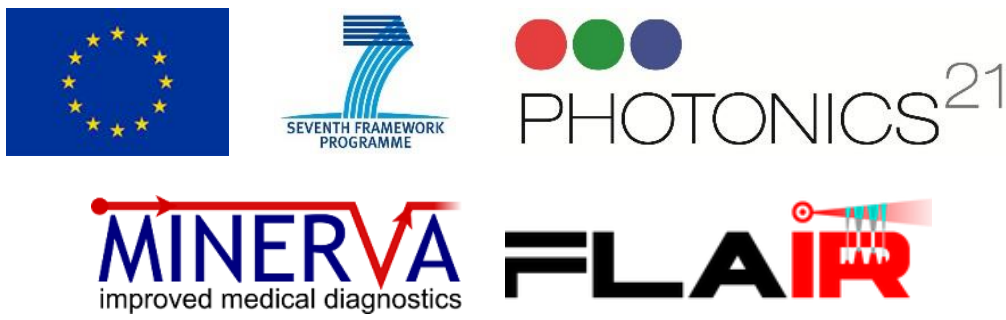

\section{ACKNOWLEDGEMENTS}

This work was supported by the European Commission through the Framework Seven (FP7) project MINERVA[27] grant number 317803 and European Union's Horizon 2020 research and innovation program under grant agreement No 732968 project FLAIR and under the Photonics21 Photonics Public Private Partnership system[28]. The authors also acknowledge financial support from Innovation Fund Denmark, project Light \& Food (J. No. 132-2012-3) and project ShapeOCT (J. No. 4107-00011A).

\section{REFERENCES}

[1] Moselund, P.M. et al. "Highly Stable, All-fiber, High Power ZBLAN Supercontinuum Source Reaching $4.75 \mu \mathrm{m}$ used for Nanosecond mid-IR Spectroscopy," in ASSL Congress, paper JTh5A.9 (2013).

[2] Moselund, P.M., et al. "All-fiber mid-IR supercontinuum: a powerful new tool for IR-spectroscopy," Proc. of SPIE 97030B-1 (2016)

[3] Kilgus, J., et al., "Application of supercontinuum radiation for mid-infrared spectroscopy," SPIE Photonics Europe 98990K (2016) 
[4] Farries, M., et al., "Mid infra-red hyper-spectral imaging with bright super continuum source and fast acoustooptic tuneable filter for cytological applications," Journal of Physics: Conference Series, 619, p. 012032 (2015)

[5] Lindsay, I. D., et al., "Towards supercontinuum-driven hyperspectral microscopy in the mid-infrared," Proc. of SPIE 970304-1 (2016)

[6] Farries, M., et al. "Fast hyper-spectral imaging of cytological samples in the mid-infrared wavelength region," Proc. of SPIE Vol 100600Y-1 (2017)

[7] Seddon, A., et al., "Towards the mid-infrared optical biopsy," Proc. of SPIE 970302-1, (2016)

[8] Seddon, A., et al., "Mid-infrared Spectroscopy/Bioimaging: Moving toward MIR optical biopsy," Laser Focus World, 52, p. 50 (2016)

[9] Ramsay, J., et al. "Generation of infrared supercontinuum radiation: spatial mode dispersion and higher-order mode propagation in ZBLAN step-index fibers", Opt. exp., 21, p. 10764 (2013)

[10] Dupont, S. et al. "Up-conversion of a megahertz mid-IR supercontinuum," JOSA B, 30, p. 2570 (2013)

[11] Huot, L., "Upconversion imaging using an all-fiber supercontinuum source,” Opt. lett., 41, p. 2466 (2016)

[12] www.h2020flair.eu/

[13] Dumas, P. and Miller, L., "Biological and Biomedical Applications of Synchrotron Infrared Microspectroscopy," Journal of Biological Physics 29, p. 201 (June 2003).

[14] Smith, G. D. "Infrared microspectroscopy using a synchrotron source for arts-science research," JAIC, Volume 42, p. 399 (2003)

[15] Marcelli, A. et al. "Biological applications of synchrotron radiation infrared spectromicroscopy," Biotechnology Advances 30, p. 1390, (2012)

[16] Quaroni, L. et al., "The Infrared Beamline at the Swiss Light Source: a Tool for Chemical Microanalysis," CHIMIA 64, 475 (2010).

[17] Kubat, I et al., "Thulium pumped mid-infrared 0.9-9 $\mu \mathrm{m}$ supercontinuum generation in concatenated fluoride and chalcogenide glass fibers," Opt exp. 22, p. 3959 (2014)

[18] Kubat, I. et al. "Mid-infrared supercontinuum generation in concatenated fluoride and chalcogenide glass fibers covering more than three octaves," CLEO STh3N.1 (2014)

[19] Petersen, C R et al., "Spectral-temporal composition matters when cascading supercontinua into the midinfrared," Opt exp, 24, p. 749 (2016)

[20] Petersen, C R et al., "Mid-IR supercontinuum generation beyond $7 \mu \mathrm{m}$ using a silica-fluoride-chalcogenide fiber cascade," SPIE BiOS 97030A (2016)

[21] Maria, M. et al. "A comparative study of noise in supercontinuum light sources for ultra-high resolution Optical Coherence Tomography," Proc. of SPIE Vol,10056,,100560O-1, (2017)

[22] Bondu, M. et al., "Using a single supercontinuum source for visible multispectral photoacoustic microscopy and 1300 nm optical coherence tomography," European Conference on Biomedical Optics 1041507, (2017)

[23] Maria, M. et al., "Q-switch-pumped supercontinuum for ultra-high resolution optical coherence tomography," Opt. Lett., 42, p. 4744 (2017)

[24] Bondu, M., et. Al. "Multispectral photoacoustic microscopy and optical coherence tomography using a single supercontinuum source," ISSN 2213-5979 (2017)

[25] Bondu, M. et al., "High energy supercontinuum sources using tapered photonic crystal fibers for multispectral photoacoustic microscopy," Journal of biomedical opt., 21, p. 061005 (2016)

[26] Bondu, M. et al. "Development and noise study of an all fibre-based high energy supercontinuum source using tapered photonic crystal fibre for multimodalities," CLEO EU, CJ-P-25, (2017)

[27] www.minerva-project.eu

[28] www.photonics21.org 